\title{
Monitoring and Controlling System for an IoT Based Smart Home
}

\author{
Soyoung Hwang \\ Department of Software \\ Catholic University of Pusan, South Korea \\ soyoung@cup.ac.kr
}

\begin{abstract}
The Internet of Things (IoT) is the interconnection of uniquely identifiable embedded computing devices within the existing Internet infrastructure. IoT is expected to offer advanced connectivity of devices, systems, and services that go beyond machine-tomachine communications and covers a variety of protocols, domains, and applications. The major objectives for IoT are the creation of smart environments and self-aware things for climate, food, energy, mobility, digital society and health applications. The main IoT applications are smart energy, smart health, smart home/buildings, smart transport, smart industry and smart city. This paper proposes a monitoring and controlling system for an IoT based smart home. This paper also discusses architecture for an IoT based smart home and presents a prototype system design and implementation result.
\end{abstract}

Keywords: IoT (Internet of Things), smart home, architecture, monitoring, control, Arduino, smartphone

\section{Introduction}

The Internet has drastically changed the way we live, moving interactions between people at a virtual level in several contexts, spanning from the professional life to social relationships. The Internet of Things (IoT) has the potential to add a new dimension to this process by enabling communications with and among smart objects, thus leading to the vision of "anytime, anywhere, any media, anything" communications [1].

The IoT is defined by ITU (International Telecommunication Union) and IERC (European Research Cluster on the Internet of Things) as a dynamic global network infrastructure with self-configuring capabilities based on standard and interoperable communication protocols where physical and virtual "things" have identities, physical attributes and virtual personalities, use intelligent interfaces, and are seamlessly integrated into the information network [2]. The IoT is a novel paradigm that is rapidly gaining around in the scenario of modern wireless telecommunications. The basic idea of this concept is the pervasive presence around us of a variety of things or tags, sensors, actuators, mobile phones, etc. - which, through unique addressing schemes, are able to interact with each other and cooperate with their neighbors to reach common goals [3].

The major objectives for IoT are the creation of smart environments and self-aware things for climate, food, energy, mobility, digital society and health applications. The main IoT applications are smart energy, smart health, smart home/buildings, smart transport, smart industry and smart city $[4,5]$. This paper proposes a monitoring and controlling system for an IoT based smart home. It discusses architecture for an IoT based smart home and presents prototype system design and implementation result.

The remainder of this paper is organized as follows. Section 2 presents architecture for an IoT based smart home. It considers the layered architecture and the conceptual architecture. In section 3, it discusses prototype system design for an IoT based smart home. It proposes service scenario and system structure. Section 4 presents prototype 
system implementation result using Arduino and smartphone. Finally, this paper is concluded in section 5 .

\section{Architecture for an IoT Based Smart Home}

Several organizations are working to equip homes with technology that enables the occupants to use a single device to control all electronic devices and appliances. The solutions focus primarily on environmental monitoring, energy management assisted living, comfort, and convenience [6].

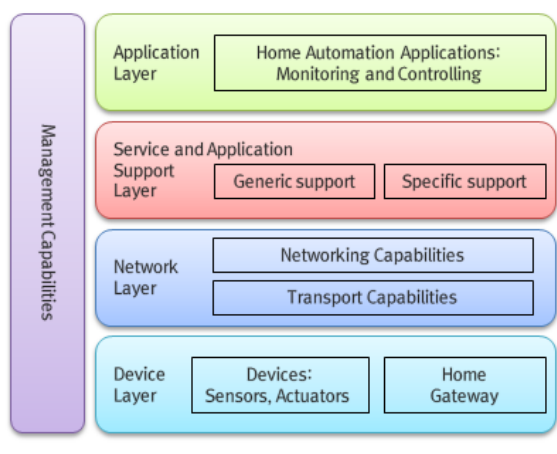

Layered architecture

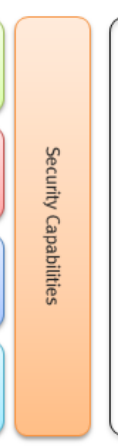

Figure 1. Architecture for an loT based smart home

Architecture for an IoT based smart home is presented in fig. 1. The layered architecture for home automation refers to the IoT layered architecture of ITU-T. The layered architecture for a smart home is partitioned into four layers, from a device layer at the bottom to the application layer at the top, as follows:

\section{Device layer:}

It defines sensors, actuators and home gateway for an IoT based smart home service.

\section{Network layer:}

It defines format and delivery of data packets for smart home service.

\section{Service and application support layer:}

It is about generic and specific support for service and application of smart home.

\section{Application layer:}

It defines detailed and application specific information for an IoT based smart home.

Management and security capabilities cover all layers.

The conceptual architecture is based on a network of intelligent sensors and actuators to provide information about the state of the home and to control the state of the home. These sensors and actuators monitor and control systems such as energy generation and metering; heating; ventilation, and air conditioning (HVAC); lighting and security. Occupants can use smart devices such as smartphones and tablets as a terminal. A home gateway collects and processes sensed data and relays information about the state of the home and control message of users. 


\section{Prototype System Design}

This section discusses a prototype system design for an IoT based smart home. A service scenario and system structure is presented.

\subsection{Service Scenario}

To design a monitoring and controlling system for smart home, a service scenario is defined. The overall service scenario is shown in fig. 2.

Occupants can monitor and control the status of a home through a smartphone, which is used as a user terminal. Environmental information of home is composed of temperature, humidity, and illuminance. Occupants can control the operation of an airconditioner or heater depending on the condition of temperature and humidity, and control the lighting depending on the illuminance. In addition, it senses when there is intrusion from the outside and inform the intrusion to the user based on the security settings.

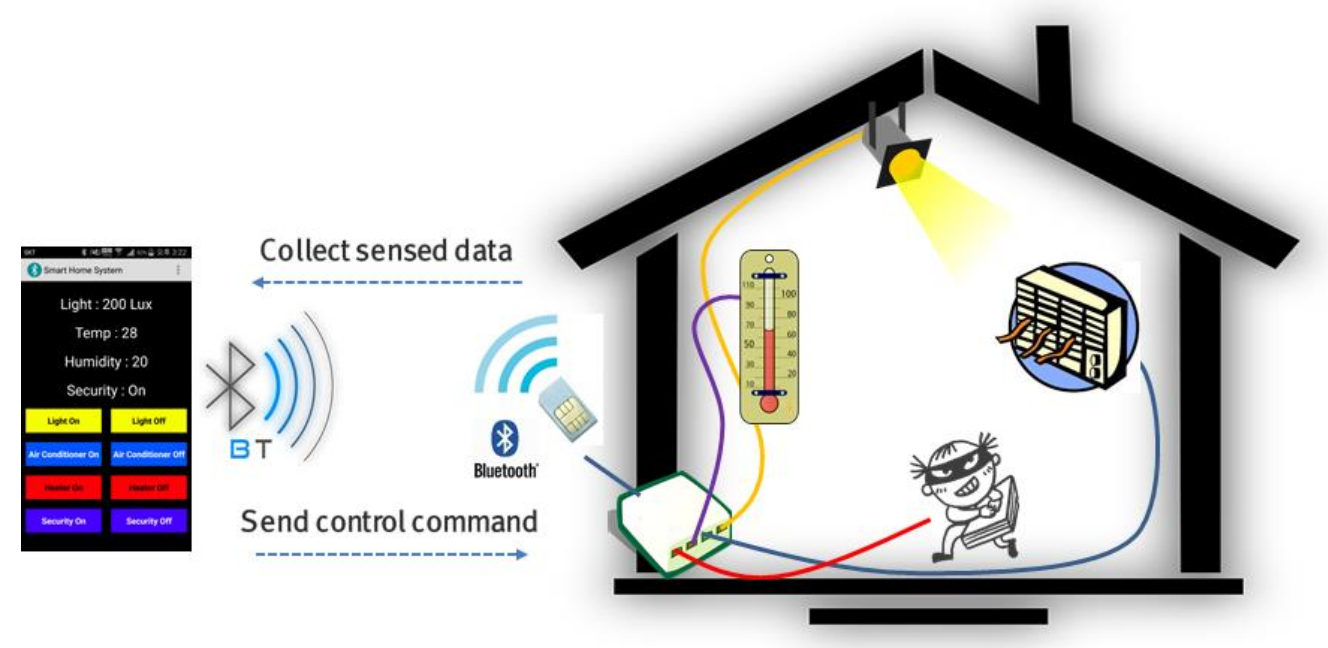

Figure 2. Service Scenario

\subsection{System Structure}

In this sub-section, a structure of the system for home monitoring and controlling is defined according to the previously proposed service scenario. It also describes the functions of each component constituting the system.

Fig. 3 shows the overall structure of the monitoring and controlling system for an IoT based smart home. 


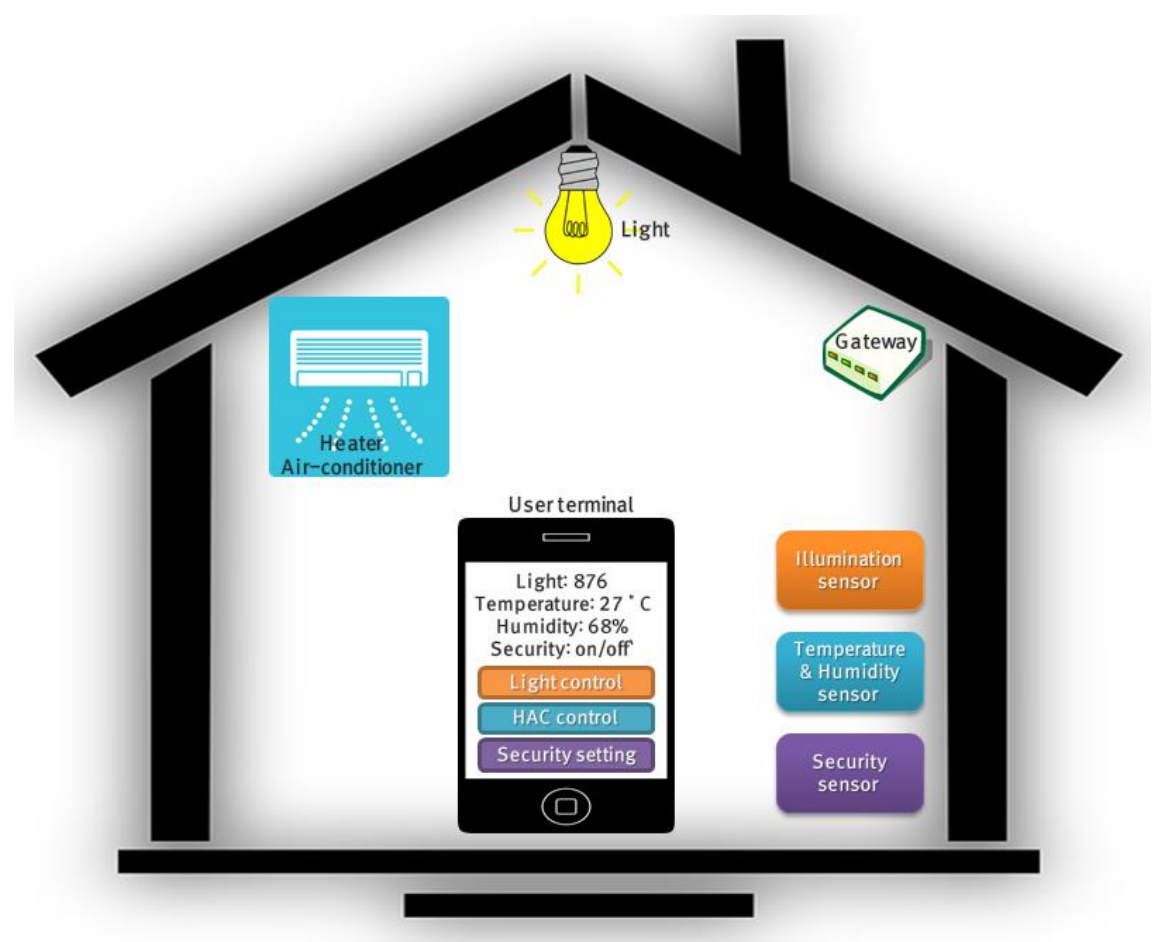

Figure 3. System structure for smart home

The system is composed of three components such as sensors, gateway, and smartphone.

\section{Sensors:}

Various sensors installed in a house collect environmental information of the home such as temperature, humidity, illumination and so on. They also transmit the collected data to the gateway.

\section{Gateway:}

It conveys information collected from sensors to the smartphone and controls each device according to the control message received from the smartphone.

\section{Smartphone:}

The smartphone works as a user terminal. It shows environmental information of the home received from the gateway to the user with a GUI and provides an interface for controlling devices such as heater, air conditioner, lighting, and so on. In addition, it can detect an intrusion from the outside through the security settings.

\section{Implementation Result}

This section describes the implementation details of the monitoring and controlling system for the smart home and its test results.

\subsection{Implementation Details}

The proposed system is implemented by using Arduino and smartphone. Arduino is an open-source prototyping platform based on easy-to-use hardware and software. Arduino boards are able to read inputs - light on a sensor, a finger on a button, or a Twitter 
message - and turn it into an output - activating a motor, turning on an LED, publishing something online. It can be activated by sending a set of instructions to the microcontroller on the board [7].

Table 1 summarizes the functions and meaning of devices used in the prototype system implementation, which are described as follows:

Table 1. Devices for prototype system

\begin{tabular}{|c|c|c|}
\hline Device & Function & Meaning \\
\hline Illumination sensor & Sensing luminosity & - \\
\hline $\begin{array}{c}\text { Temperature \& humidity } \\
\text { sensor }\end{array}$ & $\begin{array}{c}\text { Sensing temperature and } \\
\text { humidity }\end{array}$ & - \\
\hline \multirow{2}{*}{ RGB LED } & Output & Blue: Air-conditioner on \\
\cline { 2 - 3 } & & Red: Heater on \\
\cline { 2 - 3 } & Sensing distance & White: Light on \\
\hline Ultrasonic sensor & Output & $\begin{array}{c}\text { Alarming of intrusion } \\
\text { detection }\end{array}$ \\
\hline Piezo Buzzer & &
\end{tabular}

\section{Illumination sensor:}

It senses the illumination value using the Arduino ADC and converts it into units of lux.

\section{Temperature and humidity sensor:}

DHT11 sensor is used. It collects temperature and humidity data using the Arduino ADC.

\section{RGB LED:}

It is used for representing the operation of heater, air conditioner and lighting. It has three LEDs such as red, green, blue. It can express a variety of colors by adjusting the three colors of LED. It is controlled by PWM of Arduino.

\section{Ultrasonic sensor:}

This sensor measures distance. It determines that there is an intrusion or not through detecting the opening and closing of windows when the security setting is on.

\section{Piezo buzzer:}

It performs an alarming function by generating a sound when the ultrasonic sensor detects an intrusion.

Table 2 shows hardware-specific interface between Arduino-Uno and each module used in the system implementation. 
Table 2. Hardware Interface Description

\begin{tabular}{|c|c|c|}
\hline Module & Module Pin & Arduino-Uno Pin \\
\hline \multirow{2}{*}{ Bluetooth } & RXD & D3 \\
\hline & TXD & D2 \\
\hline Illumination sensor & Pin 2 & A5 \\
\hline $\begin{array}{c}\text { Temperature \& humidity } \\
\text { sensor }\end{array}$ & OUT & $\mathrm{A} 2$ \\
\hline \multirow{3}{*}{ RGB LED (Light) } & RED & D11 \\
\hline & GREEN & D10 \\
\hline & BLUE & D9 \\
\hline \multirow{3}{*}{$\begin{array}{c}\text { RGB LED (Air } \\
\text { conditioner and Heater) }\end{array}$} & RED & A1 \\
\hline & GREEN & A3 \\
\hline & BLUE & $\mathrm{A} 4$ \\
\hline \multirow{2}{*}{ Ultrasonic sensor } & TRIGGER & D7 \\
\hline & ECHO & D8 \\
\hline Piezo Buzzer & BUZ & D6 \\
\hline
\end{tabular}

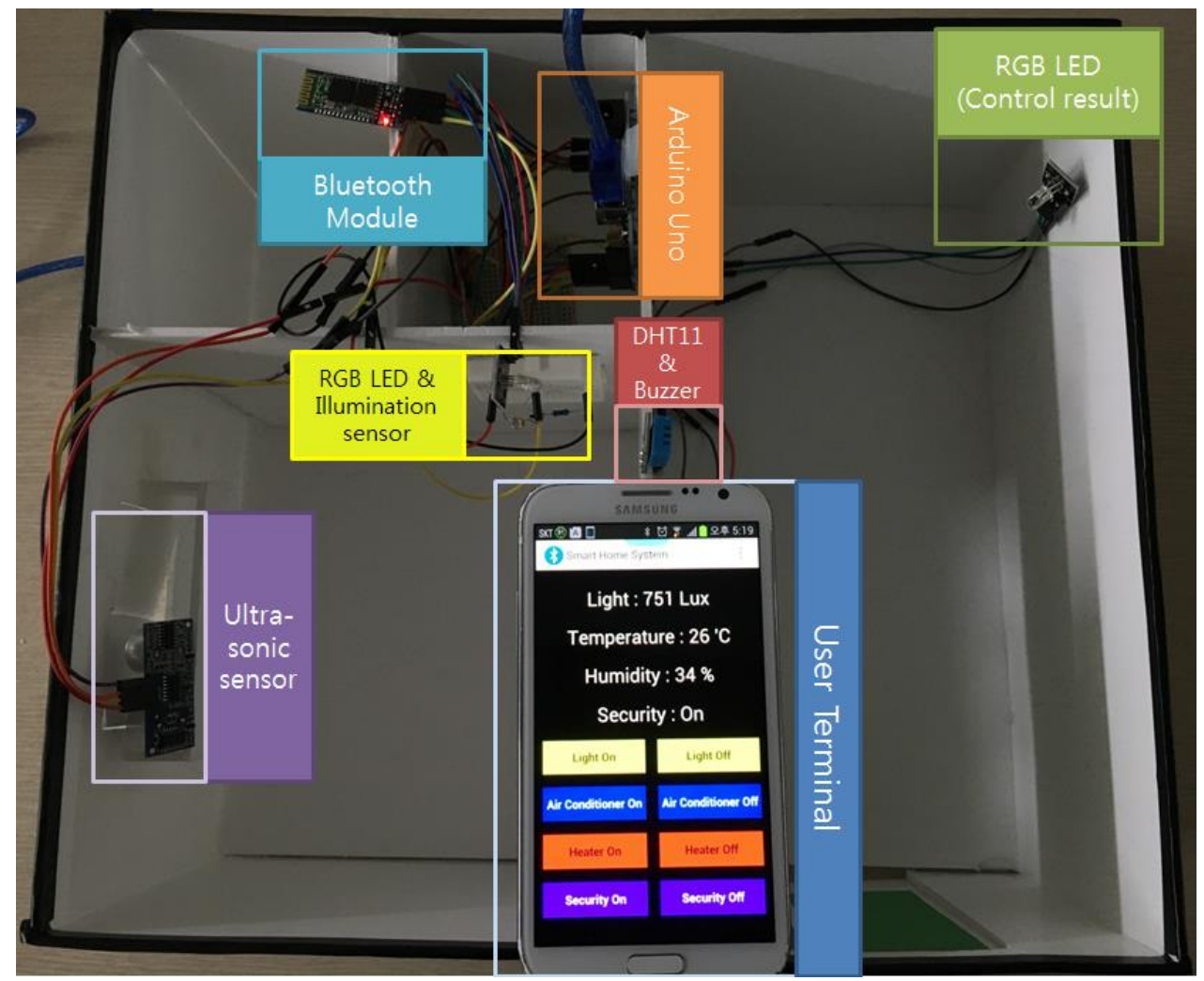

Figure 4. Implementation Result 
Fig. 4 shows a prototype system implementation result. Temperature and humidity sensor, illumination sensor, and ultrasonic sensor are all connected to the Arduino-Uno board, which collects the environmental data of the home. The Arduino-Uno works as a gateway. Bluetooth module provides the communication function between the ArduinoUno and the smartphone. A mobile application is implemented for home monitoring and controlling.

The environmental information collected by the various sensors is transmitted to the smartphone through the gateway and is shown to the user with a GUI. When a button on the smartphone application is pressed according to the needs of users, the command is passed to the Arduino-Uno and it operates the RGB LEDs or the buzzer.

\subsection{Test Result}

This sub-section presents the operation test result of the implemented system. First, a user performs the Bluetooth communication connection between the smartphone and the Arduino. When the connection is established, the user can check the environment information collected by sensors and can perform various kinds of control commands.

Fig. 5 illustrates the light control test result. Users can check the light intensity value depending on the amount of the light intensity. If it is determined that the light intensity is low, users click the light-on button on the smartphone, then the LED corresponding to lightbulb turns on and the light intensity value goes up.

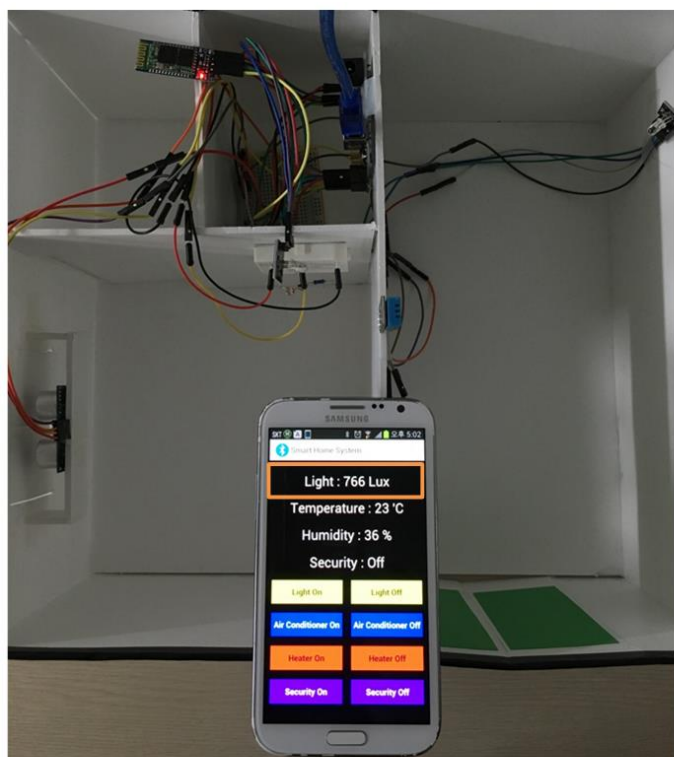

Before light control

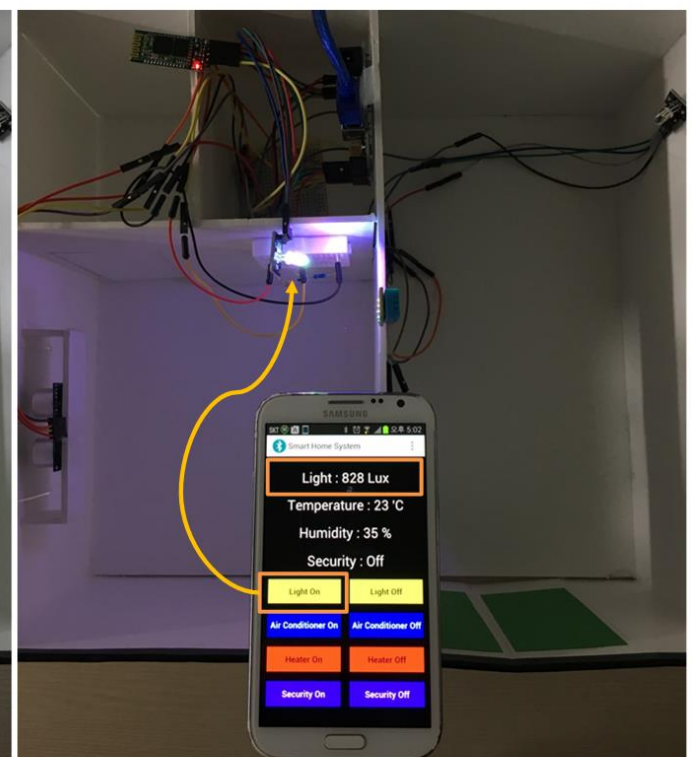

After light control

\section{Figure 5. Light Control Test Result}

Fig. 6 and fig. 7 show air conditioner and heater control test result. As defined in implementation details, an RGB LED is used to represent the operation of the air conditioner and heater. Blue light symbolically represents the operation of the air conditioner, and Red light represents the operation of the heater. Users can check temperature and humidity value on the smartphone and control the air conditioner and heater by pressing control button on the smartphone. 


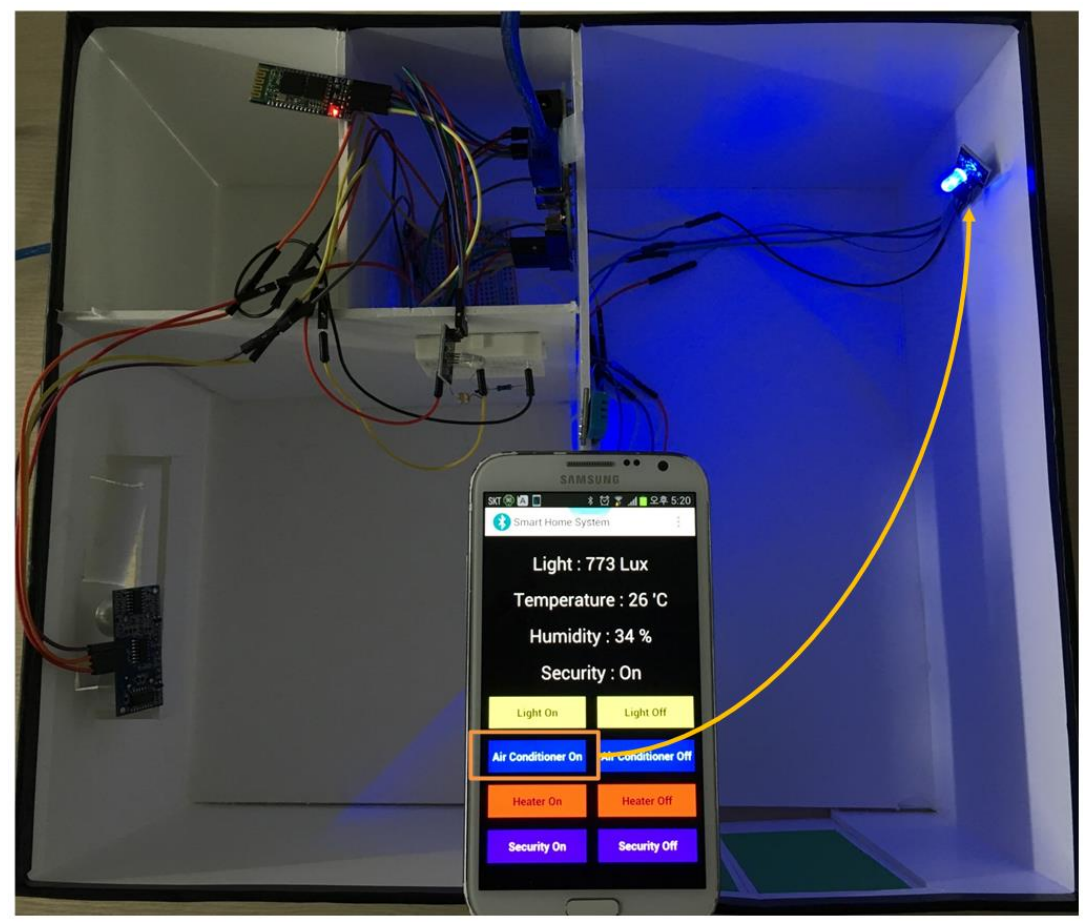

Figure 6. Air Conditioner Control Test Result

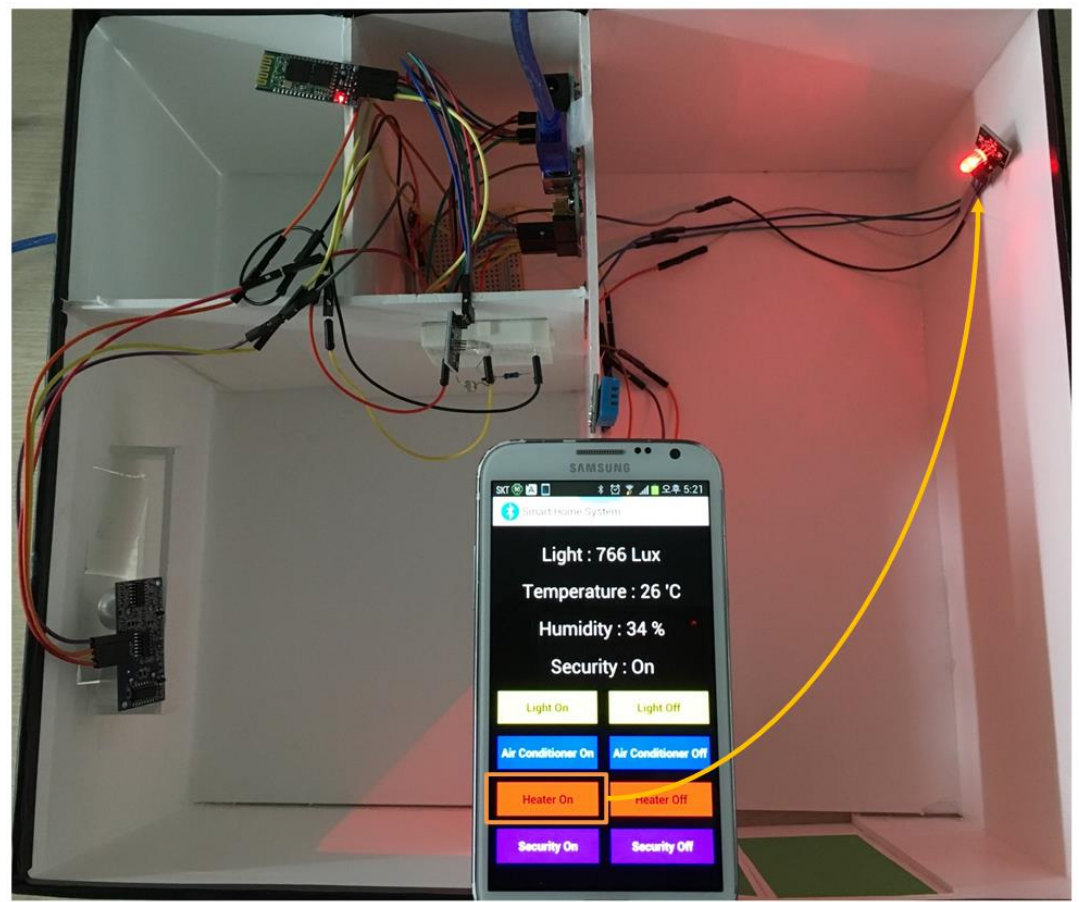

Figure 7. Heater Control Test Result

Fig. 8 shows the test result of the intrusion detection into the house from the outside. The user can set the function of the security on the smartphone. The ultrasonic sensor can sense the movement of the window. When the security function is setup and the ultrasonic sensor senses the movement of the window, users can detect the intrusion through alarming of the buzzer and vibrating of the smartphone. 


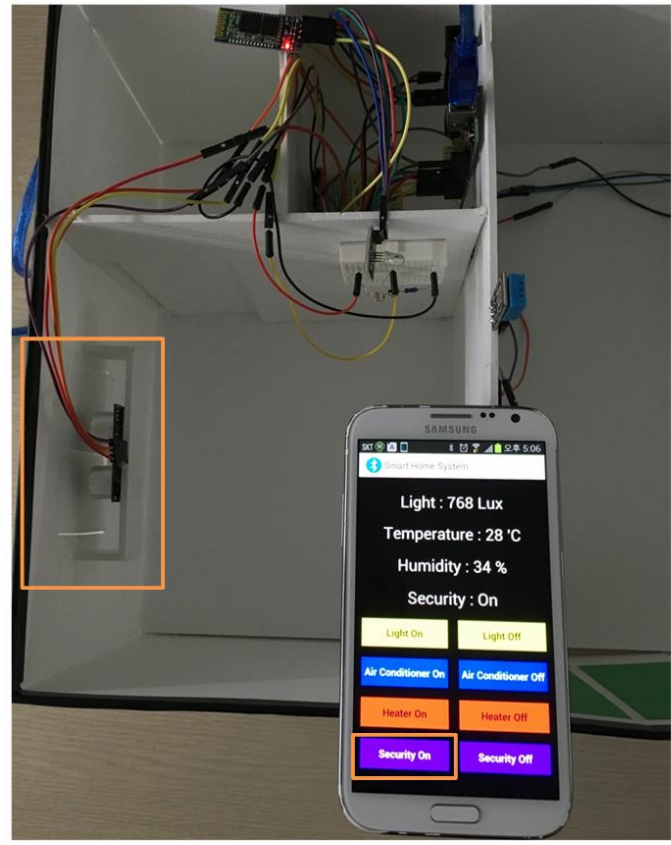

Before intrusion detection

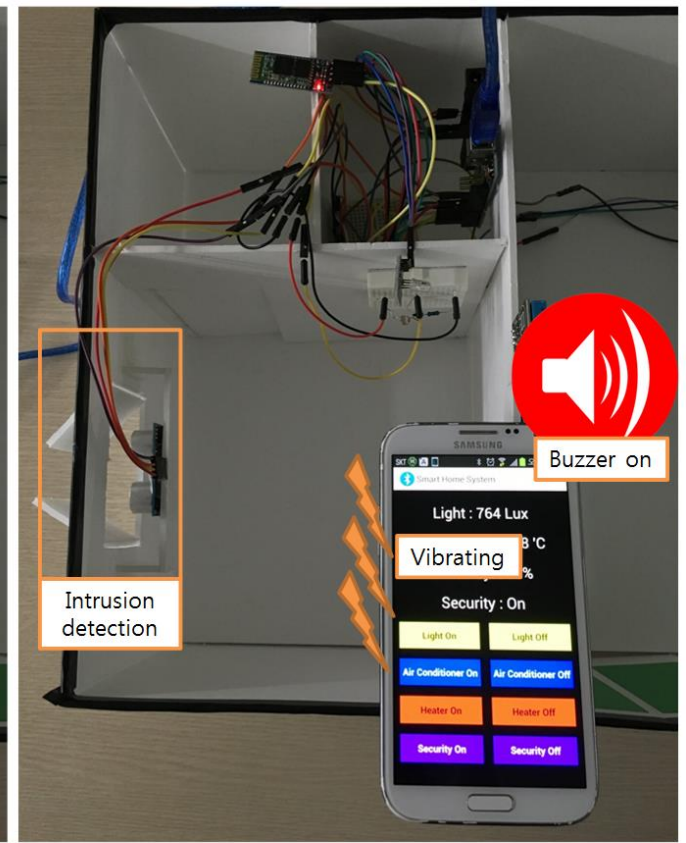

After intrusion detection

Figure 8. Security control test result

In this section, the implementation details of the monitoring and controlling system for smart home and test result are discussed. The proposed system is implemented by using Arduino and smartphone. Test results show that the implemented prototype system works properly.

\section{Conclusions}

The Internet of Things may represent the next big leap ahead in the ICT field. The possibility of seamlessly merging the real and the virtual world, through the massive deployment of embedded devices, opens up new and exciting directions for both research and business [8]. The main IoT applications are smart energy, smart health, smart home/buildings, smart transport, smart industry and smart city. This paper proposed a monitoring and controlling system for an IoT based smart home. It discussed architecture for an IoT based smart home and presented system design and implementation results.

It proposed a layered architecture and a conceptual architecture for an IoT based smart home. The layered architecture for home automation refers to the IoT layered architecture of ITU-T. The conceptual architecture is based on a network of intelligent sensors and actuators to provide information about the state of the home and to control the state of the home.

This paper defined a service scenario and system structure to design a prototype system, and the prototype system was implemented by using Arduino and smartphone.

Temperature and humidity sensor, illumination sensor, and ultrasonic sensor were all used to collect the environmental data of the home. The Arduino-Uno worked as a gateway. Bluetooth module provides the communication function between the ArduinoUno and the smartphone. A mobile application was implemented for home monitoring and controlling.

The environmental information collected by the various sensors was transmitted to the smartphone through the gateway and was shown to the user with a GUI. When a button on the smartphone application is pressed according to the needs of users, the command is 
then passed to the Arduino-Uno, which then operates the RGB LEDs or the buzzer. Test results show that the implemented prototype system works properly.

\section{References}

[1] L. Atzori, A. Iera and G. Morabito, “The Internet of Things: A survey," Computer Networks, vol. 54, no. 15, (2010), pp. 2787-2805.

[2] O. Vermesan and P. Friess, Editors, "Internet of Things - From Research and Innovation to Market Deployment", River Publishers, Aalborg, Denmark, (2014).

[3] D. Giusto, A. Iera, G. Morabito, and L. Atzori, Editors, "The Internet of Things", Springer, New York, (2010).

[4] T. Robles, R. Alcarria, D. Martin, M. Navarro, R. Calero, S. Iglesias and M. Lopez, "An IoT Based Reference Architecture for Smart Water Management Processes", Journal of Wireless Mobile Networks, Ubiquitous Computing, and Dependable Applications, vol. 6, no. 2, (2015), pp. 4-23.

[5] M.Hassanalieragh, A. Page, T. Soyata, G. Sharma, M. Aktas, G. Mateos, B. Kantarci and Silvana Andreescu, "Health Monitoring and Management Using Internet-of-Things (IoT) Sensing with Cloudbased Processing: Opportunities and Challenges", Proceedings of the 12th IEEE International Conference on Services Computing, New York, USA, (2015), June 27-July 2.

[6] "Connected Devices for Smarter Home Environments," in IBM Big Data \& Analytics Hub [Online], 2014, Available: http://www.ibmbigdatahub.com/blog/connected-devices-smarter-home-environments.

[7] “Arduino - Introduction”, in Arduino [Online], Available: http://www.arduino.cc/en/guide/introduction.

[8] D. Miorandi, S. Sicari, F. D. Pellegrini and I. Chlamtac, "Internet of things: Vision, applications and research challenges", Ad Hoc Networks, vol. 10, no. 7, (2012), pp. 1497-1516.

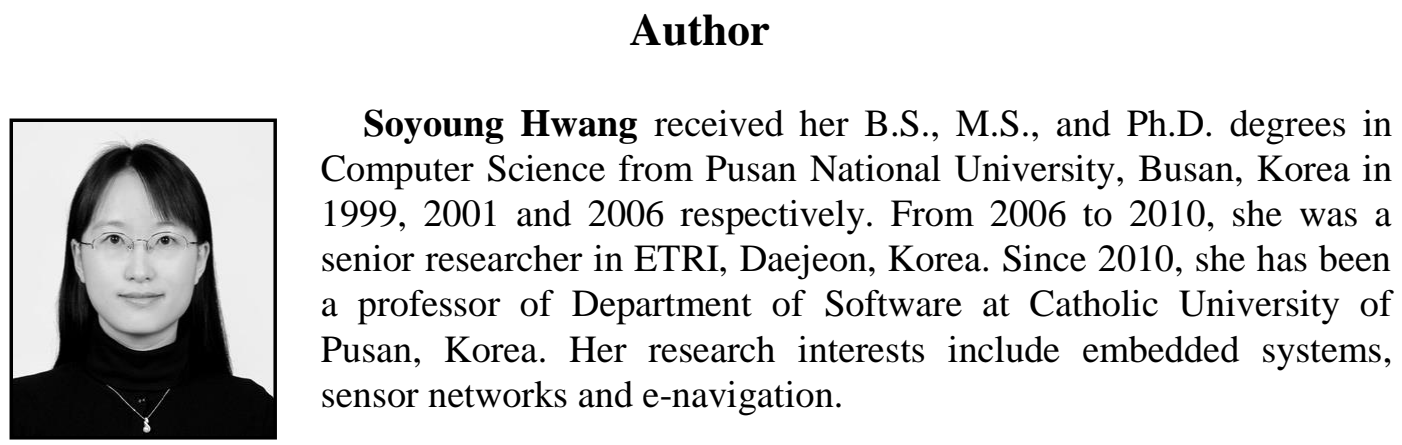

